\title{
Correction: Ecological sensitivity within human realities concept for improved functional biodiversity outcomes in agricultural systems and landscapes
}

\section{Melissa Anne Beryl Vogt (D)}

Correction to: Humanities and Social Sciences Communications https://doi.org/10.1057/s41599-021-00837-3, published online 02 July 2021.

Several minor typographical errors were mistakenly left uncorrected at the proofing stage. These have now been corrected.

Published online: 27 July 2021

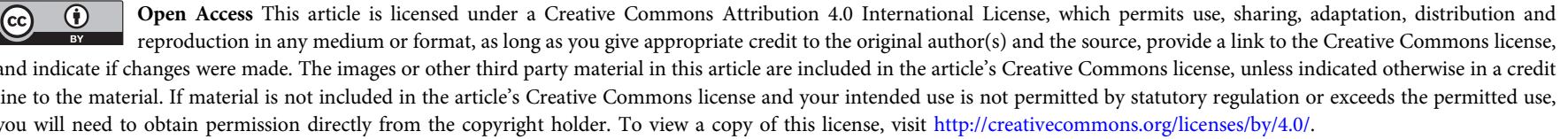
you will need to obtain permission directly from the copyright holder. To view a copy of this license, visit http://creativecommons.org/licenses/by/4.0/.

(C) The Author(s) 2021 